\title{
Los inicios de la asistencia social en Colombia
}

\author{
Beatriz Castro Carvajal.
}

\begin{abstract}
Social marginality was not absent in XIX century Colombian society. Therefore, the need of an organized response to this kind of problems arose. This reflection examines the period in which Colombian social assistance emerges and takes form. For this purpose the following article presents the main orientations and discussions that guided the various approaches to social work: charity, public assistance and social action. The creation process of urban institutions, both public and private, and their different forms of assistance is also presented.
\end{abstract}

En la segunda mitad del siglo XIX “lo social” aparece con cierta importancia en la sociedad colombiana. La pobreza surge como una preocupación que se expresa en la prensa y en escritos importantes de la época, como La miseria en Bogotá de Miguel Samper, ${ }^{1}$ tal vez, entre otras cosas, por la visibilidad de la pobreza en los principales centros urbanos y por el temor, muchas veces expresado de que el país se acercara a la situación de pauperismo europeo y que por lo tanto surgieran levantamientos parecidos a los de la Comuna de Paris. ${ }^{2}$ Es cierto que para esa época el desarrollo socioeconómico de país era precario como bien lo han señalado Marco Palacios y Frank Safford: “Al ingresar Colombia al siglo XX era palpable el escaso desarrollo del capital humano, físico y financiero. Entre los países latinoamericanos, el país ocupaba uno de los últimos sitios de

\footnotetext{
${ }^{1}$ Samper, Miguel, La miseria en Bogotá, Universidad Nacional, Bogotá, 1969. Publicado por primera vez en 1867 por solicitud de la Sociedad de San Vicente de Paúl para conmemorar sus primeros diez años de fundación.

${ }^{2}$ Ver: Martínez, Frédéric, El Nacionalismo Cosmopolita. La referencia europea en la construcción nacional en Colombia, 1845-1900, Banco de la República e Instituto Francés de Estudios Andinos, Bogotá, 2001. (Capítulo 8).
} 
acuerdo con los índices de alfabetización, dotación de ferrocarriles, caminos, puentes, puertos, urbanización, bancos y redes de sucursales bancarias. Todo esto a pesar de que las exportaciones se habían reactivado en la segunda mitad del siglo XIX, particularmente entre 1850 y 1882 ". 3

Para resolver el problema de la pobreza tanto el Estado como las instituciones que se iban fundando para ayudar a los pobres produjeron ciertas orientaciones. Las nociones claves que orientaron las prácticas adelantadas por el Estado y por las instituciones para afrontar el problema de la atención a los más necesitados en la segunda mitad del siglo XIX $\mathrm{y}$ en la primera mitad del siglo $\mathrm{XX}$ en Colombia fueron las dos parejas caridad beneficencia y acción social - asistencia pública. El paso paulatino, a veces opaco, de una pareja a la otra constituye, en el campo de la atención, un rasgo distintivo. Se trata entonces de una transformación conceptual e ideológica de consecuencias esenciales sobre las formas de atención a los pobres, sobre el tipo y conformación de las instituciones que se desenvolvían en este campo de actividad y sobre las relaciones entre el Estado y las instituciones. La consideración de este fenómeno puede ser útil para poner de presente cambios mayores que ya se venían produciendo en el país. El problema resulta pues un objeto que debe merecer sin lugar a dudas una consideración especial.

Existe sin embargo otro concepto que aparece cuando se hace referencia a la problemática del tratamiento de la pobreza. Se trata del concepto de filantropía. Se hace necesario entonces explicar las razones del silencio frente a este importante concepto de las ciencias sociales, para mostrar que se trata de una opción deliberada que tiene en cuenta tanto las características del período estudiado, como los marcos mentales de la sociedad examinada. La palabra filantropía y el concepto de filantropía son dos realidades semánticas y conceptuales que tienden a ser hoy muy utilizadas en el trabajo de las ciencias sociales. Según la reconocida Enciclopedia Internacional de las Ciencias Sociales, los términos de filantropía y caridad se han utilizado por mucho tiempo indistintamente, pero los cambios de actitud social y cultural que se han producido con respecto al fenómeno de la beneficencia -como una actividad en general estatal y pública-, han dado a la caridad una connotación un tanto peyorativa, de modo que gradualmente se ha abierto paso entre los

\footnotetext{
${ }^{3}$ Palacios, Marco y Frank Safford, Colombia. País fragmentado, sociedad dividida. Su historia, Norma, Bogotá, 2002. (p. 467).
} 
especialistas el concepto de filantropía, como más adecuado para el adelanto de un trabajo de análisis descriptivo e interpretativo, y no simplemente valorativo. La filantropía es definida entonces como la disposición o dedicación activa a promover la felicidad y el bienestar a sus congéneres, definición que incluye el concepto moderno de la labor caritativa que atiende más al bienestar total del individuo que el simple alivio de la miseria. $^{4}$

Respecto de lo que parece ser el uso concreto de la palabra filantropía en Colombia en la segunda mitad del siglo XIX y principios del siglo XX, según lo muestra la documentación examinada, podemos indicar que tal palabra era utilizada para describir la actividad de las personas que daban dinero o algún tipo de ayuda para el socorro de los necesitados, pero sin que esa ayuda diese lugar a ninguna participación directa en las actividades que económicamente se apoyaban. Por su parte, las personas y grupos que participaban directamente en las actividades de caridad o beneficencia calificaban a las personas dedicadas a la filantropía -en el sentido definido-, de manera despectiva, presentándoles incluso algunas veces reclamos morales, que aparecían como un cuestionamiento de esa clase de actividad. Tales reclamos estaban dirigidos sobre todo a las fiestas o eventos fastuosos que se realizaban para recoger fondos con el objetivo de ayudar a los pobres. Así por ejemplo en una nota del Boletín de la Sociedad de San Vicente de Paúl encontramos un texto que sirve para ilustrar lo que pensaban las personas dedicadas a las prácticas caritativas respecto de aquellas que se dedicaban a las actividades denominadas como filantrópicas.

Tal fue la invención de la filantropía, palabra pagana y de resultados no menos paganizantes. Ésta es la que ha presumido en los tiempos modernos suplantar a la caridad, pretendiendo sus honores... ¿Cuánto tiempo habéis gastado en los Asilos de Beneficencia regalando con las dulzuras de vuestra caridad a los huérfanos y desvalidos? ¿Cuántas noches habéis pasado velando a la cabecera de los moribundos? ¿Cuántas veces se os ha visto por los salones de los hospitales consolando y sirviendo a los enfermos? ¿Os habéis llegado alguna vez al lecho de algún apestado o colérico?[...]

Pero ¡Ah!, si tienen la nobleza de confesar la verdad, contestarán: No, nada de eso hemos hecho, pero sin embargo, dicen, nadie podrá negarnos que ejercemos la caridad de otra manera y que trabajamos para los pobres. Ah, sí, es verdad; no puede negarse que algo han hecho en favor de los miserables.

\footnotetext{
${ }^{4}$ Enciclopedia Internacional de las Ciencias Sociales, Ediciones Aguilar, Madrid, 1974. (Tomo 4, pp. 281-
} 287). 
Dejándose llevar de los impulsos de su tiernísimo corazón, han inventado bailes, espectáculos y corridas de toros, que llevan el título de funciones de beneficencia, cuando no de caridad, en las que los concurrentes a ellas no ejercen en realidad, ningún acto de caridad, pero en cambio se divierten mucho; que sino se divirtieran no darían seguramente su dinero...

Por eso la caridad es por naturaleza humilde, y la filantropía ruidosa; aquella busca el bien del prójimo; ésta sólo se busca a sí misma; aquella besa la mano del que recibe para no humillarse y endulzar su pena, ésta da con soberbia y ostentación ofendiendo la dignidad del que recibe: aquella consuela al atribulado y llora con el afligido; ésta sólo podrá darle una limosna pero a condición de que huya de su presencia y de que le deje gozar de su acto de generosidad; aquella da lo mejor que tiene el alma y el corazón; ésta lo más vil y despreciable, un puñado de metal. ${ }^{5}$

De esta manera el concepto de filantropía, que generalmente en otros contextos ha sido entendido como sinónimo de caridad, en la sociedad colombiana en la segunda mitad del siglo XIX y principios del siglo XX, parece haber tenido un sentido diferente de aquel que se daba al término caridad. La filantropía es una palabra poco utilizada entre nosotros, en ese período, por lo menos, y que aparece realmente en contadas ocasiones en los escritos sobre la atención a la población "desvalida”, a diferencia de caridad, palabra que es mencionada de manera permanente. Es notable también que el concepto de caridad no haya recibido nunca adjetivos peyorativos, y que más bien siempre recibiera valoraciones positivas y fuera una acción recomendada, digna de gentes socialmente respetables preocupadas por el bien de sus semejantes.

La palabra y la noción de caridad son uno de los términos claves de esta época para el tratamiento de la pobreza en el país. Ocurre además que se trata de una noción que permaneció durante todo el período que hemos considerado como pilar esencial de las formas de ayuda diversas a los pobres, precisamente en un período rico y variado desde el punto de vista de la creación de instituciones y formas específicas de ayuda a los pobres. Sin embargo, ni la palabra ni la realidad conceptual a que se hace referencia con el vocablo

\footnotetext{
${ }^{5}$ Boletín de la Sociedad de San Vicente de Paúl, no. 230, Bogotá, 1931, pp. 32 y 33. Citado en adelante como BSVP.
} 
“caridad” representaban en esta época una novedad absoluta. Se trata por el contrario de una noción que había venido utilizándose desde la época colonial.

Definir el concepto de caridad es una tarea difícil, como según lo reconocen connotados especialistas del tema, entre ellos el gran historiador de la pobreza en el Medioevo y los albores del Mundo Moderno, Bronislaw Geremek, quien tan solo puede escribir al respecto, como resumen de sus búsquedas: "la caridad es un sentimiento y un comportamiento complejo[s]”. ${ }^{6}$ La caridad se define como una virtud con vastísimas cualidades y alrededor de ella se relaciona un sinnúmero de actitudes. La caridad verdadera es entonces industriosa, abnegada, paciente, benigna, humilde y desinteresada, no busca el provecho, todo lo sobrelleva, todo lo soporta. Además a la caridad se le establece un número infinito de atributos, dones y virtudes que la hacen casi milagrosa o al menos la representan como una actitud que se encuentra un tanto distante de lo habitual y terrenal. Para decirlo con las palabras de un escritor local, político y hombre de Estado, que vivió en el período que consideramos y quien se ocupó largamente del problema, y posiblemente resuma bien las concepciones sobre la caridad de esa época y sociedad:

Porque ella [la caridad] es la sola que establece a un tiempo la fraternidad natural y la necesidad de las desigualdades sociales; que prescribe la resignación a los pobres y la limosna a los ricos; que a los unos les pone por modelo la pobreza de Jesucristo, viajero de este mundo que no poseyó ni siquiera una choza, y a los otros la munificencia del Creador. ${ }^{7}$

Como aparece claro en el texto antes citado de Marco Fidel Suárez -aunque bajo la forma de una ideología-, la caridad es siempre una relación social, un hecho que no puede tener realización más que a través de una interacción social, una “acción doble”, que supone el concurso de quien ofrece y de quien recibe. Pero como esta doble acción no solo brinda beneficios materiales, sino que posibilita el perfeccionamiento espiritual del que da y la “cristianización” y moralización del que recibe, es un caso típico y ejemplar de lo que los antropólogos han denominado como "hecho social total", 8 pues se trata de un tipo de

\footnotetext{
${ }^{6}$ Geremek, Bronislaw, La piedad y la horca. Historia de la miseria y de la caridad en Europa, Alianza Editorial, Madrid, 1989. (p. 267).

${ }^{7}$ Suárez, Marco Fidel, “Discurso en la Sociedad de San Vicente de Paúl el 22 de julio de 1883”, en: Obras de Marco Fidel Suárez, Editorial Librería Voluntad, Bogotá, 1958. (pp. 1087-1104).

${ }^{8}$ Mauss, Marcel, "Ensayo sobre los dones, motivo y forma del cambio en las sociedades primitivas", en: Mauss, Marcel, Sociología y antropología, Tecnos, Madrid, 1971. (pp. 155-257).
} 
relación que compromete tanto dimensiones materiales como mentales, tanto dimensiones económicas como simbólicas.

Según Natalie Z. Davis, el sistema de dones católicos estaba basado en la noción antigua de que las cosas sagradas, el regalo de Dios por excelencia no se podía vender. La idea permaneció firmemente en las enseñanzas y en la ley canónica. La Iglesia era entonces la institución en donde los regalos circulaban, por ejemplo se intercambiaban las velas por la fe, se daba comida a las almas en el Día de los Muertos, se rezaba por las almas que estaban en el purgatorio; a los santos se les daba estatuas y velas para que ellos intercedieran con Dios. ${ }^{9}$ También había intercambios entre los laicos y los clérigos, los laicos daban cálices, vestiduras, estandartes y dinero, y los sacerdotes retornaban con oraciones y liturgias en las misas. Los clérigos podían usar estas donaciones no solamente para las misas sino también para la reparación de las iglesias, para apoyar el culto y para ayudar a los pobres, que también glorificaban a Dios. Pero los laicos también daban ayudas a los pobres de forma directa y lo hacían generalmente en los lugares santos. Siempre había la esperanza de la gratitud de los que lo recibían, y que estos se sintieran obligados a rezar por las almas de los donadores. Pero todas estas donaciones, eran finalmente donaciones a Dios. El meritorio acto de donar podría atraer la atención de Dios y tal vez servir para la salvación del alma del católico. Adicionalmente, el dar debía estar acompañado siempre de cierto sacrificio que los donantes trataban de cumplir.

Según la historiadora, San Francisco de Asís en el siglo XIII planteó la posibilidad de dar directamente a los pobres y no darles a través de la Iglesia, ampliando de esta forma el espacio del dar y reforzando el sentido de la caridad. Esta propuesta fue posible en la medida que se fueron creando instituciones para ayudar a los pobres. La donación se vuelve más distante que cuando la donación se realizaba directamente por medio de limosnas, pero se intentaba de esta forma hacerla más organizada. No obstante, está posibilidad nunca suplantó las otras formas da dar donación directamente a la Iglesia. De todas formas la obligación de dar en el catolicismo cualquiera fuera la forma que se escogiera estaba directamente vinculada al camino de la salvación y se ubicaba entre los polos de la reciprocidad y la gratitud.

\footnotetext{
${ }^{9}$ Davis, Natalie Z, The Gift in Sixteenth-Century France, The University of Wisconsin Press, Wisconsin, 2000. (Capítulo 7).
} 
Ahora bien, a pesar de todas estas evoluciones de dirección secular, la concepción religiosa de la caridad continuó siendo predominante, o por lo menos en todas las concepciones de la caridad parece haberse mantenido su viejo fondo cristiano. Como sabemos, en la concepción religiosa de la caridad estaba implícita la idea de que quien ofrecía el don, la ofrenda, la ayuda, recibiría una recompensa por la dádiva, fuera en este mundo o en el venidero. Como lo señalaba de manera clara un Boletín de la Sociedad de San Vicente de Paúl, haciendo una aplicación precisa de preceptos eclesiásticos generales a la situación concreta en que se desarrollaba su operación caritativa:

\begin{abstract}
¿Sabéis que cada mes todo socio de San Vicente de Paúl puede ganar una indulgencia plenaria aplicable a las almas del purgatorio, si asiste a todas las Juntas de conferencia o por lo menos si son cuatro a tres? ¿Sabéis que está concedido el mismo beneficio espiritual a todo socio que asista a la Comunión y a cada una de nuestras Juntas anuales, o sea a los retiros y a la misa de comunión que los clausura? ¿Sabéis que cada vez que participáis en las diferentes tres obras de la Sociedad, asistencia a las Juntas, visita de pobres, a los presos, a los enfermos del hospital, asistencia a la misa por un consocio o por un padre fallecido, etc., etc., se os concede una indulgencia de siete años y siete cuaresmas? ¿'Sabéis de todas las indulgencias plenarias o parciales concedidas a vosotros, a vuestros padres, a los socios honorarios, a los bienhechores de vuestra conferencia, a los padres que visitáis? ${ }^{10}$
\end{abstract}

Este significado de recompensa futura pervive desde luego en la ideología moderna de la beneficencia, pero ya no se piensa tanto en recibirla en el otro mundo, sino en éste, sea bajo la forma de una simple satisfacción personal que depara el sacrificio y el deber cumplido, o como una recompensa más tangible en forma de beneficios directos o indirectos, beneficios de una gran variedad y de imposible definición uno a uno, pero que sin duda se encuentran vinculados a lo que genéricamente llamamos el poder, en sus dimensiones material o simbólica.

La noción de caridad tal como circuló y fue utilizada en Colombia en el período que nos ocupa, está de manera clara ligada a los preceptos del cristianismo católico. Durante el período colonial, la Monarquía española otorgó protección y apoyo a la evangelización y a la organización de la Iglesia; la educación y los pocos establecimientos de salud y amparo existentes fueron delegados administrativamente a la Iglesia. La ruptura política representada por la independencia hispanoamericana significó una posibilidad de

\footnotetext{
${ }^{10}$ BSVP, no. 241, Bogotá, 1932, (pp. 4 y 5).
} 
replantearse las relaciones de las nuevas naciones en formación con la Santa Sede. Los nuevos gobernantes, dentro del respeto por la religión, querían conservar el control sobre la Iglesia -el patronato-, sin garantizarle situaciones de privilegio o monopolio. De ahí que una de las grandes discusiones políticas de la primera mitad del siglo XIX tuviera como objeto el lugar y la función de la Iglesia en la sociedad.

Por su parte la Iglesia Católica quería liberarse del control estatal, pero al mismo tiempo pretendía mantener su situación privilegiada, y su monopolio frente a otras confesiones religiosas. Al mismo tiempo, los nuevos Estados carecían de plena legitimidad social y política, sus recursos fiscales eran exiguos, estaban agobiados por deudas, y sus aparatos de hegemonía cultural de masas y de control administrativo eran precarios o casi inexistentes. Esto contrastaba con la situación de la Iglesia Católica, cuya posición económica era relativamente sólida, gozaba de gran aceptación social y contaba con un número si no suficiente sí apreciable de clérigos y religiosas para garantizar la continuidad de su presencia e influjo efectivos en cada región del país. ${ }^{11} \mathrm{Al}$ mismo tiempo, la Iglesia había acumulado durante toda la sociedad colonial una sólida experiencia pedagógica y educativa y un sistema de relaciones con los vecindarios y comunidades que la convertín en elemento básico de todo proyecto de integración social. ${ }^{12}$

En Colombia a mediados del siglo XIX, con las reformas liberales, que incluían la desamortización de los llamados “bienes de manos muertas”, la abolición de los diezmos, el control de los fondos clericales por las cámaras distritales y la elección de los párrocos por el cabildo municipal, y que además se vieron acompañadas con la nueva expulsión de la Compañía de Jesús, el concepto de caridad entró en discusión. La polémica se centraba en dos conceptos: la caridad y la beneficencia, que se pensaban como dos conceptos excluyentes, o por lo menos no complementarios, y su discusión estaba relacionada con el debate sobre la secularización del Estado, en el sentido elemental de una forma de administración pública, controlada por “civiles” y manejada con independencia de la Iglesia y de sus jerarquías. Para entender el fondo y los matices del debate hay que tener en cuenta que, si bien la beneficencia también se define como una "virtud", como una forma de hacer

\footnotetext{
${ }^{11}$ Castro, Beatriz, "Caridad y beneficencia en Cali, 1848 - 1898”, Boletín Cultural y Bibliográfico, vol. XXVII, no. 22, Bogotá, 1990, (pp. 67-80).

${ }^{12}$ Ver: Melo, Jorge Orlando, “La República Conservadora, 1880-1930”, en: Melo, Jorge O., Colombia Hoy, Siglo XXI Editores, Bogotá, 1978, (pp. 52-101).
} 
el bien e incluso como el propio ejercicio de la caridad, existe una diferencia grande respecto a la forma de realización "del bien”, ya que la definición de beneficencia liga el "acto de dar" con la existencia de instituciones que lleven a cabo las actividades benéficas, tratándose, en general, de instituciones estatales, o por lo menos controladas y vigiladas por los gobiernos. De esta manera, el "proyecto de beneficencia" no aparece ligado ni condicionado a la Iglesia, y en principio se encuentra despojado de las connotaciones espirituales-religiosas que aparecen de manera evidente en la idea tradicional de caridad, tratándose más bien del ejercicio de una virtud secular, o más estrictamente de un deber ciudadano y estatal. La diferencia entre caridad y beneficencia, pues, no se encuentra particularmente del lado de su consideración como una virtud o no, del lado de su consideración como una práctica socialmente aprobada o no, sino en relación con su lugar en la estructura de la sociedad y del Estado, con su definición como una virtud secular y como una obligación social.

Es claro que por los objetos con los cuales se relacionaba, por las tradiciones sociales que ponía en tela de juicio, por las fuerzas sociales que comprometía y por el momento de su aparición en el contexto de un Estado que aún no definía sus rasgos centrales, el debate respecto de las nociones de caridad y beneficencia en Colombia no fue solo un debate intelectual y doctrinario, sino que fue ante todo un debate político y un elemento que produjo oposiciones y divisiones en torno de "lo social". Por fuerza de las circunstancias y de las tradiciones culturales de la sociedad en donde el debate se desarrollaba, la defensa de la noción y del proyecto de "caridad” terminó relacionándose con una posición de apoyo a la Iglesia y ligada al partido conservador, mientras que el alinderamiento con la noción y el “proyecto de beneficencia” terminó relacionándose con una idea "civilista” de la sociedad, con un cierto impulso a los procesos recién iniciados de secularización, y por lo tanto "representándose” como una afiliación al proyecto del liberalismo más radical, aunque en términos efectivos ninguna de las dos posiciones fuera así de clara y de excluyente. Como corresponde a nuestras tradiciones y particularmente a un siglo como el XIX, dominado por la pasión política, la polémica fue ardua, sobre todo entre 1851 y 1876, años en los cuales las reformas emprendidas por el liberalismo radical en el gobierno afectaron significativamente los privilegios que la Iglesia tenía desde el período colonial, ya que al proyecto reformista de los liberales se le sumó el decreto orgánico de instrucción pública 
primaria, que trataban de acabar con el resto de privilegios económicos de la Iglesia y el control que ejercía sobre la educación.

Las medidas liberales de reforma repercutieron sobre los establecimientos de atención a los pobres que dependían de alguna asociación o comunidad religiosa, pero que en algunos casos también pertenecían simultáneamente a alguna instancia estatal. En un primer momento estos establecimientos pasaron a pertenecer totalmente a los gobiernos municipales. Posteriormente y de manera progresiva los hospitales, hospicios e incluso escuelas pasaron a ser administrados por comunidades religiosas que fueron llamadas por el Estado para que realizaran contratos con los gobiernos locales y se encargaran de la administración de dichos establecimientos. Cuando se lograron los arreglos entre el Estado y las órdenes religiosas para el manejo de los establecimientos, arreglos forzados por la inexperiencia del Estado, enfrentado a las presiones y experiencia de la Iglesia en este terreno, el debate público respecto de los conceptos de caridad y beneficencia disminuyó y tendió a desaparecer, y ocurrió que la noción de caridad se revitalizó y volvió a primer plano, fortalecida por la presencia renovada de la Iglesia y de las fuerzas sociales que la apoyaban. $^{13}$

Se puede decir como balance provisional que las reformas liberales contribuyeron a transformar la noción tradicional de caridad en dirección de la noción de beneficencia, al haber logrado crear un sistema de atención de los pobres en manos del Estado, aunque por fuerza de las circunstancias esto significó entrar en acuerdos con las instituciones y comunidades religiosas para su administración. La diferencia central respecto de lo obtenido podría expresarse diciendo que las actividades de atención de pobres dirigidas por el Estado no ofrecen como su programa la ayuda domiciliaria a los que tienen necesidad, sino que funda o crea establecimientos especializados con tal fin, y se compromete en un programa de auxilios económicos para con las instituciones, que cumplen de manera autónoma con esta labor. Al parecer el cambio sustancial que se presentó respecto de la

\footnotetext{
${ }^{13}$ De manera similar sucedió en México, en donde las reformas de secularización fueron más radicales que en Colombia. Silvia M. Arrom señala al respecto: "En conclusión, es difícil atribuirle a los liberales la transformación de la caridad católica en beneficencia pública. Este proceso lo iniciaron los reyes ilustrados a mediados del siglo XVIII. Los liberales solamente siguieron los sólidos pasos borbones, y los avanzaron con débiles pasos adicionales. Por consiguiente las reformas de Juárez no fueron el cambio de rumbo radical proclamado por la historiografía oficial”. Arrom, Silvia M., “ ¿De la caridad a la beneficencia? Las reformas de asistencia pública desde la perspectiva del Hospicio de Pobres de la Ciudad de México, 1856 - 1871”, en Illanes, Carlos y Ariel Rodríguez (ed.), Ciudad de México: instituciones, actores sociales y conflicto político, 1774 - 1931, Colegio de Michoacán y UNAM, México, 1997.
} 
noción originaria de caridad, en el momento en que el Estado asume la nueva dirección de un programa de "beneficencia pública”, tiene que ver con la decisión del Estado de centrarse en la ayuda institucional y no participar en la ayuda domiciliaría, como otros Estados lo hacían y lo habían hecho. ${ }^{14}$ Podemos afirmar entonces que en 1870 el gobierno liberal introdujo lo "social” dentro de la agenda de su gobierno. Era la primera vez que lo “social” entraba con notoriedad en la agenda del gobierno colombiano, aspecto que no volvió a ser excluido de la agenda de los siguientes gobiernos; por el contrario, fue paulatinamente recogido, incluso por los gobiernos conservadores, aunque los recursos asignados para este rubro hubieran sido mínimos en comparación con otros gastos estatales.

La ayuda institucional antes de 1870 era poca y se encontraba concentrada en los grandes centros urbanos, esencialmente en establecimientos como los hospitales, atendiendo a los enfermos pobres, y excepcionalmente la Casa de Refugio de Bogotá, fundada a finales del siglo XVIII como hospicio. Después de 1870 se pueden observar cambios en la ayuda institucional, principalmente la fundación y creación de establecimientos de mayor especialización, sobre todo en los centros urbanos más importantes, tratando se asegurar el dominio de los establecimientos y las responsabilidades de los gobiernos locales, regionales y nacionales.

Los mayores esfuerzos de la ayuda institucional durante los gobiernos liberales se centraron en la educación. Fueron separados el campo de la educación del de la beneficencia, creando la Junta de Instrucción Pública, responsable de promover la educación, principalmente las escuelas primarias gratuitas. Para los niños y jóvenes la instrucción se centraba en la educación básica más un adiestramiento en artes y oficios; la de las niñas se centraba también en educación básica pero complementada con actividades domésticas; para los artesanos el énfasis estaba en las formas mínimas de entrenamiento en distintos oficios manuales, complementado con algo de instrucción básica. Los establecimientos para la educación de los niños y jóvenes fueron las escuelas de primaria

\footnotetext{
${ }^{14}$ Es importante resaltar y señalar que en muchos países europeos y en los Estados Unidos, la ayuda domiciliaria fue el centro de las políticas estatales de ayuda a los pobres. Ver Innes Joanna, "State, Church and Voluntarism in Europe Welfare, 1690-1850", en; Cunningham, Hugh e Innes Joanna (ed.), Charity, Philanthropy and Reform. From 1690s to 1850, Macmillan Press, Londres, 1998, (pp. 15-65), y Adonica, Lui, "Political and Institutional Constraints of Reform: The Charity Reforms Failed Campaigns Against Public Outdoor Relief, New York, 1874-1898”, Journal of Political History, vol. 7, no. 3, 1995, pp. 341-364.
} 
gratuitas y algunos orfanatos, para los jóvenes y trabajadores fueron las escuelas de artes u oficios, los colegios dominicales y los nocturnos.

Presentar un cuadro completo de las escuelas primarias en todo el país es una tarea difícil. El primer esfuerzo efectivo por establecer escuelas primarias gratuitas se efectuó durante el gobierno liberal en 1876. Antes de esta reforma hubo dos intentos pioneros en educación después de la Independencia. En 1826, en el gobierno del General Francisco Paula Santander, se creó la Dirección de Instrucción Pública para promover la educación popular. Las escuelas primarias recibieron colaboración con libros y materiales educativos, pero las escuelas gratuitas fueron un sueño aplazado. En 1842 el presidente Mariano Ospina Rodríguez declaró la educación primaria gratuita, los padres tenían que enviar a todos sus hijos a las escuelas y éstas tenían la obligación de recibir a todos. Sin embargo la puesta en marcha fue principalmente un deseo, pues el Estado no tuvo los recursos necesarios para llevar a cabo esta propuesta. ${ }^{15}$

Para 1847, según Frank Safford, se calculan en el país 659 escuelas primarias privadas y 474 escuelas primarias gratuitas, de las cuales las primeras tenían 7.611 estudiantes y las segundas $21.517 .{ }^{16}$ La realidad era que muchas de las escuelas privadas estaban en manos de órdenes religiosas. En 1876, cuando el gobierno liberal quiso poner en marcha su programa educativos, se generaron fuertes controversias que se pueden explicar por las disputas políticas entre los dos partidos, por la alianza de la Iglesia católica con el partido conservador, por la introducción de nuevos métodos de enseñanza que fueron vistos como “extranjeros y anticatólicos” y por los nuevos impuestos que se ordenaron para llevar a cabo el programa. ${ }^{17}$ Para 1876 se estiman 1.646 escuelas primarias con 79.123 estudiantes; pero la mayoría fue cerrada durante la guerra civil de 1876, y fue sólo durante la década de 1880 que las escuelas primarias pudieron recuperar parte de su dinámica. ${ }^{18}$

\footnotetext{
${ }^{15}$ Ver: Helg, Aline, La Educación en Colombia, 1918-1957. Una historia social y política, Cerec, Bogotá, 1987; y González, Fernán Educación y Estado en la historia de Colombia, Cinep, Bogotá, 1979.

${ }^{16}$ Safford, Frank, El ideal de lo práctico. El desafío de formar una élite técnica y empresarial en Colombia, Ancora, Bogotá, 1989, (p. 79)

${ }^{17}$ Un ejemplo de los descontentos por los impuestos mencionados se puede encontrar en el periódico Los Principios, Cali, 26 de noviembre de 1876.

18 M. Rausch, Jane M.,La Educación durante el Federalismo, Instituto Caro y Cuervo-Universidad Pedagógica Nacional, Bogotá, 1993, (Capítulo 5). Los departamentos que fueron líderes en las escuelas primarias fueron Antioquia, Santander, Boyacá y Cundinamarca.
} 
En 1883 había en Colombia 1.297 escuelas primarias con 68.261 niños. ${ }^{19}$ En la Constitución de 1886 la educación se declaró libre, pero no obligatoria, y fue organizada en concordancia con la religión católica. Algunos historiadores han señalado que la decisión de entregar buena parte de las instituciones educativas a la Iglesia católica en Colombia, en esta época, tiene explicaciones prácticas, como lo sugiere Germán Colmenares: "Investigaciones recientes se inclinan a concluir que, en el caso de la educación, se impusieron más bien consideraciones pragmáticas. El Estado no poseía los recursos para sostener el fervor que habían mostrado los radicales por una educación laica”. ${ }^{20}$ En un Reporte británico de 1887 sobre Colombia se afirmaba que la instrucción pública se está extendiendo, que muchas de las escuelas primarias son patrocinadas por el Gobierno y que en general la educación muestra progresos. ${ }^{21}$

Al lado de las actividades del Estado, asociaciones laicas, como la Sociedad de San Vicente de Paúl desde su fundación en 1857, tuvieron un importante papel en la educación de los pobres. La sede de Bogotá comenzó con una pequeña escuela primaria con doce niñas, anexa al hospital que abrieron y sostuvieron por unos años. Después patrocinaba escuelas públicas gratuitas en seis barrios de la ciudad: Las Aguas, Egipto, La Catedral, Las Cruces, Santa Bárbara, Las Nieves, San Victorino y Santa Isabel; algunas de ellas ocasionalmente recibían ayuda de los gobiernos municipales o departamentales. ${ }^{22}$ En 1914 la Sociedad sostenía dos escuelas primarias gratuitas en Bogotá, una bajo la dirección de los Hermanos Cristianos con 300 niños, y otra pequeña, cerca de las 32 casas que la Sociedad había construido en el barrio Las Nieves. En 1917 fundaron la Escuela Modelo en edificio con suficiente espacio para que los niños pudieran hacer ejercicio y sembrar la tierra, con salones higiénicos y ventilados. En 1919 había tres escuelas primarias gratuitas que dependían del comité central de la Sociedad: una en la Calle octava con 230 niños y la Escuela Modelo con 180 niños, ambas bajo la dirección de los Hermanos Cristianos, y la escuela de las Habitaciones de los Pobres con 52 niños. ${ }^{23}$ También había escuelas que

\footnotetext{
19 Ibíd., p 185.

${ }^{20}$ Colmenares, Germán, Ricardo Rendón. Una fuente para la historia de la opinión pública, Fondo Cultural Cafetero, Bogotá, 1984, (p. 712).

${ }^{21}$ Diplomatic and Consular Reports on Trade and Finance. No. 253. Report for the year 1887 on the United States of Colombia, Londres, 1888, p. 71.

${ }^{22}$ Uribe, Antonio José, Sociedad Central de San Vicente de Paúl de Bogotá. Celebración del Quincuagésimo Aniversario 1857-1907, Imprenta Nacional, Bogotá, 1908, (p. 71.)

${ }^{23}$ BSVP, no. 111, Bogotá, 1920, p. 89.
} 
dependían de las conferencias de la Sociedad: la Conferencia de Nuestra Señora de Lourdes estableció una escuela para “niños de las clases más desvalidas”, donde se les enseñaba a leer y escribir, y se les daba comida y ropa. La Conferencia de San Pedro, con la colaboración del párroco del barrio de Egipto, fundó una escuela para los niños “que por su extremada pobreza se encuentran imposibilitados para concurrir a las escuelas públicas del municipio". 24 Igualmente en muchos colegios privados manejados por órdenes religiosas había escuelas públicas gratuitas. En 1930 la mitad de los colegios públicos y privados eran dirigidos por órdenes religiosas, y de estos 59.6\% eran para niñas y el $42.9 \%$ para niños. ${ }^{25}$ Los Hermanos Cristianos, por ejemplo, en cada colegio privado que ellos tenían a su cargo tenían una pequeña sección de educación primaria gratuita. ${ }^{26}$ También era común que en los colegios privados de niñas hubiese escuelas gratuitas para niñas pobres, como lo era en los del Sagrado Corazón de Jesús y de la Presentación. ${ }^{27}$

Otro tipo de educación para los niños pobres fue el Oratorio Festivo que establecieron los Hermanos Salesianos. Eran reuniones educativas que se llevaban a cabo los domingos y los días festivos, donde se les enseñaba religión, se realizaban juegos y deportes, se hacía drama y teatro y los niños tenían acceso a la biblioteca. Se organizaban en las parroquias de los “sectores desfavorecidos", que estaban a cargo de los Hermanos Salesianos, en coordinación con los colegios que ellos regentaban. El Oratorio del barrio Bavaria en Bogotá llegó a tener una escuela gratuita con cantina, dormitorio y un ropero, que servía por la noche como colegio para los obreros, y para actividades deportivas los domingos y días festivos. ${ }^{28}$ A mediados de 1930 se calculan 17 oratorios en Bogotá. ${ }^{29}$

Los Jesuitas, junto con la Acción Católica fundada en 1916, también organizaron Oratorios Festivos para los niños pobres y programas de bibliotecas populares en las parroquias que tenían asignadas, que incluían colegios dominicales y nocturnos para los niños y los obreros. El padre Rufino Beristain abrió ocho colegios nocturnos con el apoyo

\footnotetext{
${ }^{24}$ BSVP, no. 114, Bogotá, 1920, p. 161.

${ }^{25}$ Aline Helg, Op. Cit., p. 76.

${ }^{26}$ Ibíd., p. 78.

27 De acuerdo al periódico Los Principios, de Cali, 14 de enero de 1876, la orden religiosa del Sagrado Corazón tenía escuelas gratuitas en Popayán y Santander de Quilichao.

${ }^{28}$ Historia de Leyes, Imprenta Nacional, Bogotá, 1925, (p. 591).

${ }^{29}$ Farnell. Robert V., “The Catholic Church and Colombian education: 1886-1930, in Search of a Tradition”, Tesis doctoral, Universidad de Columbia, 1974, (p. 89).
} 
público y para 1915 tenía 1.200 obreros registrados. ${ }^{30}$ Las escuelas gratuitas también recibían colaboración de la Liga de Damas Católicas, fundada en 1924. Las señoras del Centro de Acción Católica Social de San Pedro Claver establecieron 10 escuelas primarias en Cartagena en 1919 para "enseñar a los niños y niñas más pobres la vida cristiana, los primeros rudimentos y los oficios domésticos”. ${ }^{31}$ Igualmente los Franciscanos, pero en menor medida, participaron en esta actividad; en Cali por ejemplo, fundaron varios colegios nocturnos liderados por Fray Damián González. ${ }^{32}$ En cuanto a las escuelas de artes y oficios, la Sociedad de San Vicente de Paúl fue pionera y fue tal vez su actividad en educación más importante, ofreciéndola principalmente a los jóvenes y trabajadores pobres de las ciudades más grandes. En Bogotá estableció la Escuela de Artes y Oficios en 1877, los Talleres de San Vicente en 1890, el Taller de Costura en 1890, la Escuela de Oficios Domésticos en 1894, la Escuela Práctica en 1900 y los Talleres de María Auxiliadora en 1919. ${ }^{33}$ En Medellín fundó una escuela nocturna en 1887, a la que en 1890 asistían 145 artesanos; el municipio colaboraba con libros, lápices y la iluminación. ${ }^{34}$ En 1892 creó tres más y en 1894 decidió unir todos los colegios nocturnos en uno llamado Escuela Central, con 160 artesanos. En 1907 había en Medellín siete colegios nocturnos con 682 artesanos y obreros, y recibían apoyo de los gobiernos municipales y departamentales. En Cali el principal logro de la Sociedad fue la Escuela de Artes y Oficios fundada en 1897, gracias a un legado que recibió la Sociedad, institución que en un principio dirigieron los Hermanos Maristas y que luego, en 1933, pasó a manos de los Salesianos. ${ }^{35}$

Los Salesianos -orden religiosa italiana- fueron la orden masculina más preocupada y dedicada a la educación técnica y general de los artesanos y obreros. En 1890 fundaron la Escuela León XIII en Bogotá; la mitad de los estudiantes pertenecía a grupos sociales pobres. Enseñaban la educación básica y los estudiantes podían escoger entre carpintería,

\footnotetext{
${ }^{30}$ Fernández, José María, Obra Civilizadora de la Iglesia en Colombia, Librería Voluntad, Bogotá, 1936, (p. 385).

31 Simancas, Stella, "El papel de los religiosos y de los médicos en la caridad y asistencia pública en Cartagena, 1895-1925”, Monografía, Universidad de Cartagena, 1998, (p. 88.)

${ }^{32}$ Fernández, José María, Op. Cit., p. 239.

${ }^{33}$ Uribe, Antonio José, Op. Cit., p. 71 y BSVP, no. 114, Bogotá, 1920, p. 162.

${ }^{34}$ Castro, Patricia, "Beneficencia en Medellín, 1800-1930”, Monografía, Universidad de Antioquia, 1994, (p. 24). Ver además Londoño, Patricia, Religión, cultura y sociedad en Colombia. Medellín y Antioquia 1850 1930, Fondo de Cultura Económica, Bogotá, 2004, (Capítulo 5).

35 Sociedad de San Vicente de Paúl de Cali. Primer Centenario de su fundación 1870-1970, Folleto Conmemorativo, Cali, 1970. Los primeros Hermanos Maristas llegaron a Popayán en 1889.
} 
sastrería, zapatería, talabartería, herrería o impresión. En 1905 abrieron un colegio similar en Ibagué por iniciativa del gobierno departamental. Y en 1912 fundaron el Colegio Juan Bosco que tenía 100 internos y 50 niños de familias de artesanos y obreros que recibían la educación diseñada por ellos combinando la educación básica en las mañanas y el aprendizaje de algún oficio en las tardes. En 1905 el obispo de Medellín les solicitó que abrieran un orfanato para niños pobres, que en 1921 se convirtió en la Escuela de Artes y Oficios. Después de la exitosa exhibición de sus trabajos, los gobiernos departamental y municipal decidieron transformarla en el Instituto Pedro Justo Berrio en $1926 .{ }^{36}$ En 1930 los Salesianos tenían 19 establecimientos en Colombia. ${ }^{37}$

Si bien proveer educación para los niños pobres fue uno de los objetivos de los gobiernos departamentales y municipales al principio de este periodo, su desarrollo dependió de las iniciativas de asociaciones laicas con soporte de órdenes religiosas, o de las mismas órdenes religiosas. Las escuelas de artes y oficios que impartían educación para jóvenes y adultos fueron frecuentemente una iniciativa de grupos laicos, y en algunos casos recibieron ayuda de los gobiernos departamentales y municipales. La presencia de órdenes religiosas masculinas y femeninas en la educación fue clave. Dentro las femeninas las Hermanas de la Caridad sobresalieron, siendo su contrapartida masculina los Hermanos Cristianos y los Salesianos.

Aparte de la casas de educación, los de salud y protección fueron también importantes establecimientos para la ayuda institucional. Estos establecimientos fueron impulsados por los gobiernos municipales y regionales, creados por sociedades laicas y promovidos por autoridades eclesiásticas o en algunos casos por religiosos. Durante este periodo creció la capacidad para albergar a los pobres y fue cuando se estableció la ayuda institucional con firmeza para lograr asilar y encerrar a los pobres en las principales ciudades colombianas, como en la mayoría de los países latinoamericanos. ${ }^{38}$ La mayoría de las grandes ciudades tenían un asilo para indigentes, algunas tenían también sitio para los "lunáticos” y los huérfanos, esto con apoyo público, a través de las autoridades municipales o

\footnotetext{
${ }^{36}$ Helg, Aline, Op. Cit., p. 93

${ }^{37}$ V. Farnell, Robert V., Op. Cit., pp. 85-96.

${ }^{38}$ Ver: Mead, Karen "Oligarchs, Doctors and Nuns: Public Health and Beneficence in Buenos Aires, 18801914”, Tesis Doctoral, Universidad de California-Santa Barbara, 1994; García Ponce, Antonio, Los pobres en Caracas, 1873-1907. Un estudio de la pobreza urbana, Instituto Municipal de publicaciones, Caracas, 1995; Martínez-Vergne, Teresita, Shaping the Discourse on Space. Charity and its Wards in Nineteenth-Century San Juan, University of Texas Press, Austin, 1999.
} 
departamentales. Los nuevos establecimientos que fueron creados por sociedades privadas o por individuos fueron complementarios a los esfuerzos del Estado, los que fueron siempre limitados.

Otras instituciones fueron creadas principalmente para acoger a menores de edad, al principio niños y niñas juntos, luego en 1910 todos los establecimientos se encontraban divididos por sexo. En un inicio se crearon más orfanatos para niños, pero hacia 1920, la mayoría de estos fue fundada para amparar a las niñas. Por ejemplo la Casa de Huérfanos que se fundó en 1881 bajo la dirección de la señora María de Jesús Upegui con apoyo del obispo, con el propósito de dar un sitio para vivir y brindarles alimentación, ropa y educación. Después de que los Hermanos Cristianos llegaron a Bogotá, se les encomendó la sección de niños en 1890 junto con una escuela primaria, y la sección de niñas fue trasladada a un colegio privado de las Hermanas de la Caridad. La Sociedad de San Vicente de Paúl, igualmente, organizó varios establecimientos para amparar a los niños huérfanos. En Bogotá fundo el Asilo de la Santa Infancia en 1895, con el soporte intermitente de la Junta General de Beneficencia de Cundimanarca. ${ }^{39}$ En Medellín había establecido en 1889 los Talleres de San Vicente, para acoger huérfanos entre los seis y quince años y para ofrecerles educación básica y de artes y oficios. En Bogotá se creó el Asilo de la Santa Infancia Desamparada de San Antonio en 1895, que recibió una donación en 1907 que le permitió construir un nuevo edificio y luego, bajo la dirección de Manuel María Camargo, el orfanato fue completamente reorganizado como institución de albergue y educación; en 1918 alojaba 150 niños. ${ }^{40}$ Caso similar fue el del Instituto de San Pablo construido con el legado de Lorenzo Cuéllar. ${ }^{41}$ Los niños asilados en ambos establecimientos tenían una rutina diaria estricta, fundamentada principalmente en la educación básica primaria y en el entrenamiento en oficios artesanales.

Los orfanatos femeninos compartían la mayoría de los objetivos de los masculinos, aunque hubo desde luego algunas diferencias. Las niñas recibían igualmente educación primaria básica, pero su otro aprendizaje era el de las labores domésticas; se esperaba que salieran del establecimiento a trabajar en una casa de familia buscada por la institución. La

\footnotetext{
${ }^{39}$ Archivo General de la Nación, Sección República, Fondo Policía, t. iv, fol. 680-682. Citado en adelante como AGN.

${ }^{40}$ El Catolicismo, Bogotá, 30 de noviembre de 1918.

${ }^{41}$ AGN, Sección República, Ministerio de Gobierno, t. 7, fol. 199-214.
} 
mayoría de los establecimientos eran dirigidos por damas de grupos sociales medios y altos, algunas guiadas por sacerdotes. En Bogotá, por ejemplo, fueron fundadas los siguientes orfanatos: la Casa Protectora de Niñas dirigida por Ana Vergara de Samper en 1914, la Asociación de Caridad para Niñas por Margarita Fonseca en 1919 y la Casa de María Inmaculada para el Servicio Domestico en 1921. En Medellín, tempranamente, la Casa de Beneficencia por María Escobar Uribe en 1855 y la Casa de Jesús, María y José en 1893 bajo la dirección de la Asociación del Sagrado Corazón, que posteriormente pasó a las Hermanitas de los Pobres, orden religiosa francesa. ${ }^{42}$

Hay también algunos casos de orfanatos establecidos directamente por órdenes religiosas, como los que las Hermanas de la Caridad de la Presentación establecieron en algunas salas de los hospitales que ellas dirigían en Bogotá, como ya lo hemos señalado, en Medellín en 1880 y en Cartagena en 1897. Les enseñaban los elementos de la educación básica y actividades domésticas, al tiempo que las alumnas colaboraban con las Hermanas en las actividades del hospital y llevaban una vida casi conventual. El orfanato de Cartagena consiguió un edificio nuevo en 1916 con el apoyo del gobierno gubernamental y con donaciones; en 1930 albergaba 40 niñas. ${ }^{43}$

La ayuda domiciliaria en Colombia fue liderada por la Sociedad de San Vicente de Paúl, que para 1907 tenía alrededor 50 sedes en el país, ${ }^{44}$ aunque las que realmente tuvieron una dinámica importante fueron las de Bogotá y Medellín, que concentraron sus esfuerzos en las visitas domiciliarias y ayuda a la población más necesitada a través de la donación de bonos a las familias seleccionadas. Adicionalmente se organizaron formas de repartir comida, bolsas de empleo e iniciaron programas de construcción de viviendas. ${ }^{45}$ La sede de Bogotá particularmente fue activa en el hospital de San Juan de Dios, en el campo de las consultas médicas, dispensarios y distribución de medicinas y la sede de Medellín en la Caja de Ahorros y el granero para vender alimentos más baratos a las personas favorecidas con los bonos. La Sociedad de San Vicente de Paúl de Bogotá entre 1911 y 1931 atendió

\footnotetext{
${ }^{42}$ La Asociación del Sagrado Corazón de Jesús de Medellín fue creada en 1871 por la iniciativa de señoras de la elite apoyadas por un sacerdote. Las Hermanitas de los Pobres llegaron a Colombia en la década de 1910; la congregación fue fundada en 1839 y para 1878 había 2.700 hermanas y se expandió rápidamente por fuera de Francia; en Francia fue una de las órdenes religiosas femeninas que más creció en el siglo XIX. Se dedicaban principalmente a los viejos y a las personas de las que nadie se quería hacer cargo.

${ }^{43}$ Simancas, Stella, Op. Cit., pp. 36-39.

${ }^{44}$ Uribe, Antonio José, Op. Cit., pp. 266-270.

${ }^{45}$ En Bogotá para 1931 había construido 120 casas y en Medellín en 1930, 138 casas.
} 
como promedio 320 familias por año, lo que representa alrededor de 1.300 personas atendidas. $^{46}$ A la Sociedad San Vicente de Paúl la ayuda a las familias adoptadas le significaba entregar en bonos y auxilios cerca de $\$ 10.000$ como promedio al año. Cada bono oscilaba entre un peso y veinticinco centavos. ${ }^{47}$ Aunque, claro está, una familia adoptada podía recibir varios bonos en el año. Para la sede de Medellín el promedio anual de familias atendidas entre 1912 y 1930 fue de 544. Para la Sociedad de San Vicente de Paúl de Medellín esto significó aportar \$8.311 como promedio anual en estos 19 años. Cada familia recibió anualmente \$12. La Sociedad de Medellín repartía anualmente por familia la mitad de lo que repartía la de Bogotá, aunque tenía mayor cobertura. ${ }^{48}$

II

La noción de caridad, acoplada a las necesidades sociales de la época y sin entrar en conflicto mayor con el proceso de secularización de los Estados en formación, se apoyaba particularmente en las encíclicas papales. La encíclica Rerum Novarum, presentada por el Papa León XIII en 1891, manifestaba la importancia de construir un mundo en donde la justicia social primara, como también expresaba la idea de que la manera de lograr la justicia social era por medio de la caridad cristiana. León XIII planteaba el ideal de justicia social en su encíclica Rerum Novarum de la manera siguiente:

\begin{abstract}
A los ricos y a los amos les incumbe: no tener y tratar a los obreros como se tenían en la antigüedad y se trataban a los esclavos; respetar en ellos la dignidad de persona y la nobleza que a esa persona añade lo que se llama carácter cristiano. Si se tiene en cuenta la razón natural y la filosofía cristiana, no es vergonzoso para el hombre ni le rebaja el ejercer un oficio por salario, pues le habilita el tal oficio para poder él honradamente sustentar su vida. Lo que verdaderamente es vergonzoso e inhumano es abusar de los hombres, como si no fuesen más que cosas, para sacar provecho de ellos y no estimularlos en más de lo que dan de sí sus músculos y fuerzas.

De estos deberes, los que tocan al proletariado y obreros son: poner de parte integra y fielmente el trabajo que libre y equitativamente se ha contratado: no
\end{abstract}

\footnotetext{
${ }^{46}$ Ver informes anuales de las conferencias y de la Sociedad publicados en los Boletines de la Sociedad de San Vicente de Paúl de los años señalados. El promedio que presentaban era de cinco personas por familia. Se estima que la ciudad de Bogotá tenía 235.421 habitantes en 1928.

${ }^{47}$ BVSP, no. 97, Bogotá, 1919, p. 152.

${ }^{48}$ Se estima que Medellín tenía 120.022 habitantes en 1928.
} 
perjudicar en manera alguna al capital ni hacer violencia personal a los patronos; al defender sus propios derechos, abstenerse de la fuerza, y nunca armar sediciones ni hacer juntas con hombres malvados que mañosamente les ponen delante esperanzas desmedidas y grandísimas promesas, a que se sigue casi siempre un arrepentimiento inútil y la ruina de las fortunas. ${ }^{49}$

Aunque la encíclica Rerum Novarum hacía planteamientos más relacionados con la problemática obrera, que simplemente con la existencia de los pobres, su referente social era todavía amplio, y la caridad cristiana debía ser la base, la guía, el pilar de la ayuda a los pobres. Esta encíclica era la manifestación nueva del pensamiento social católico, en un contexto moderno, en el que se trataba de enfrentar problemas inéditos. La famosa encíclica de León XIII fue una reacción más que una iniciativa, y es obvio que debajo de muchas de las preocupaciones del Pontífice estaba el temor a que el socialismo ganara la competencia por el apoyo de las masas. Pero resultaba toda una novedad que un Papa proclamase esa especie de nuevo decálogo de los derechos de los trabajadores y denunciara las injusticias sociales que acompañaban a la nueva sociedad industrial -al punto que algunos han hablado de esa encíclica como del “Anti-Manifiesto Comunista”-. La Rerum Novarum reconocía la existencia de conflictos entre los patrones y los trabajadores, conflictos que eran fruto del crecimiento de la industria, la concentración de la riqueza y el empobrecimiento de las masas. Pero la encíclica también abogaba por la intervención del Estado a favor de los trabajadores, para que estos tuvieran garantizadas unas condiciones dignas de trabajo y de vida.

Posteriormente la encíclica Quadragesimo Anno del Papa Pío XI vuelve a plantear el problema de la justicia social pero específicamente centrado en la situación de los obreros. Se retoma nuevamente la defensa de la propiedad privada y, tal vez paradójicamente, a partir de allí la construcción de un mundo más equitativo. Se busca una nueva estrategia de promoción social, pero de nuevo descansando en el proyecto de Acción Social, considerada como una acción preventiva y permanente, a diferencia de la caridad que es una actividad curativa y ocasional. Así el reto siguiente para la vieja noción de caridad fue el de ser lo suficientemente flexible para acomodarse a las nuevas exigencias sociales. Tal vez quien expresó de manera clara y sencilla la diferencia entre las diferentes modalidades de atención a los pobres fue nuevamente la Sociedad de San Vicente de Paúl:

\footnotetext{
${ }^{49}$ Bernal, José María, “Acción Social Seglar”, Revista de la Universidad Católica Bolivariana, vol. II, no. 4, Bogotá, febrero-marzo 1938, pp. 86-103.
} 
La Sociedad de San Vicente de Paúl es ante todo obra de caridad y apostolado, pero acomodándose a las necesidades y exigencias de los tiempos, es también obra de acción social.

Como obra de caridad, su principal objeto es el de visitar semanalmente, por medio de sus miembros, a los pobres en sus domicilios, a fin de llevarles, con solícito interés, socorros espirituales y materiales, así como visitarlos en los hospitales y en las prisiones, procurarles roperos, servicios médicos y boticas gratuitas, y por último, proveer al entierro de los que han fallecido y sufragios por el eterno descanso.

Como obra de apostolado, funda y sostiene escuelas cristianas gratuitas para los hijos del pueblo, catecismo, bibliotecas populares, distribuye lecturas y organiza conferencias y retiros espirituales para hombres del mundo y especialmente para los obreros.

Como obra de acción social católica, funda y sostiene talleres de artes y oficios, restaurantes escolares, patronatos de aprendices, cocinas económicas, secretarias para los pobres, cajas de ahorro y especialmente jardines obreros, y construye y administra habitaciones populares. ${ }^{50}$

La “acción” la definían los pensadores de la Acción Social Católica como “el influjo ejercido por una causa cualquiera. Fuera del influjo físico hay otro moral, y es el ejercido por un ser racional en otro racional, no ya modificando el ser físico de la persona, sino infundiéndole nuevas cualidades morales, modelando por medio de la palabra el entendimiento y voluntad ajena”. ${ }^{11}$ La Acción Social era entonces el influjo moral ejercido sobre la sociedad. El fin que se proponía la Acción Social de sus trabajos era "el conservar al pueblo en la fe y en las sanas costumbres, y el atraer a los extraviados y viciosos al buen camino, para de ese modo, conservar la paz social y procurar la salvación de las almas”. 52 Los medios para llevar a cabo el nuevo influjo moral sobre la sociedad estaban constituidos por un abanico amplio de propuestas que fueron denominadas genéricamente como obras sociales. En el Manual de Sociología Práctica de la Acción Social Católica se mencionan entre tales propuestas las siguientes: las primeras son las obras sociales de carácter general llamadas las Uniones Populares que eran encargadas de la difusión de los conocimientos sociales y la buena prensa; junto con los Secretariados Sociales que son más técnicos y que distribuyen conocimiento útiles a quien lo solicite sobre sociología o diversas industrias. Otras propuestas más particulares eran las Bibliotecas Parroquiales y las Ambulantes, los

\footnotetext{
${ }^{50}$ BSVP, no. 213, Bogotá, 1928. pp. 145 y 146.

${ }^{51}$ Fernández Jesús María, S. J., La Acción Social Católica en Colombia. Manual de sociología práctica, Arboleda \& Valencia, Bogotá, 1915, pp. 9 y 10.

52 “Acción Social Católica -1913”, Conferencias Episcopales de Colombia. 1908 - 1953, Editorial El Catolicismo, Bogotá, 1956, vol. 1, p. 50.
} 
Círculos de Estudio, las Escuelas Profesionales, Técnicas o Agrícolas y las Nocturnas y Dominicales. Las segundas eran las obras de carácter económico, que contaban con infinidad de asociaciones como fueron las Cooperativas de Producción, de Consumo, de Crédito, Mutualidades, Cajas de Ahorros, Bolsas de Trabajo, Vivienda. Se agregaban otras instituciones que tenían como fin la satisfacción de todas las necesidades a los obreros. Se trataba aquí de Patronatos para Jóvenes, los Círculos de Obreros, las Uniones Profesionales y los Sindicatos. Las terceras eran las obras diocesanas, en donde la parroquia jugaba un papel fundamental como "modelo de la organización obrera y a la vez el núcleo o célula vital del desarrollo de la vida social". ${ }^{53}$ La idea era que la parroquia fuera otro centro para desarrollar las obras sociales planteadas por la Acción Social.

El cooperar en las obras sociales se consideraba que manifestaba un espíritu cristiano y que constituía un acto de caridad. "Las obras sociales son una obra eminentemente caritativa, en todo comparable con la limosna, menos en dos cosas en que la superan: en que al socorrer la ajena miseria no se avergüenza el socorrido y en que el auxilio es más eficaz y permanente”. ${ }^{54}$ En 1931 se elaboró la Carta Apostólica del Papa Pío XI en que se recomendaba al mundo católico una cruzada de caridad y de socorros en favor de los obreros que, por falta de trabajo, no podían procurarse honradamente el pan cotidiano y que por la miseria se veían reducidos, juntamente con sus hijos, a una extrema necesidad. ${ }^{55}$ Se recomienda hacer un triduo de oraciones y rogativas, colectas promovidas por los párrocos, todo con el fin de ser repartido de manera equitativa entre los niños indigentes y desamparados.

En Latinoamérica, la Rerum Novarum obtuvo respuestas de diversa índole. Sin embargo, es posible que una de las mayores respuestas favorables y en bloque hubiera sido la que ofrecieron los jesuitas, quienes respondieron activa y prontamente a las orientaciones pontificias y consideraron que la Acción Social Católica era una estrategia indispensable para hacerse a un lugar en las organizaciones de la clase obrera y crear una presencia católica en fábricas y sindicatos. ${ }^{56}$ El lema que predominó en Colombia para apoyar la puesta en marcha de la Acción Social Católica fue: la cuestión que divide los hombres de

\footnotetext{
${ }^{53}$ Fernández, Jesús María, Op. Cit., p. 222.

${ }^{54}$ Ibídem. pp. 33 y 34.

${ }^{55}$ BSVP, no. 242, Bogotá, 1932, pp. 24 y 25.

56 John Lynch, "La Iglesia católica en América Latina, 1830-1930", en Leslie Bethell (ed.) Historia de América Latina, T. 8. Barcelona: Cambridge University Press y Editorial Crítica, 1991, pp. 65-122.
} 
nuestros días no es una cuestión de formas políticas, sino cuestión social. En Colombia, el centro vital de la Acción Católica fue el Círculo de Obreros de Bogotá, fundado en 1910 y que resulta ser aquel del que tenemos mayor conocimiento. El Círculo lo fundó el padre jesuita José María Campoamor con el objetivo de atender a los obreros de la ciudad, aunque la definición de obreros no comprendía sólo a los trabajadores de las pocas industrias que existían en aquella época en la capital, sino que incluía a todos los que hacían trabajo manual. El Círculo se inicia con la fundación de la Caja de Ahorros en 1911 y en 1913. Con los réditos de la Caja y con auxilios del Estado se compra un lote para iniciar el proyecto de la construcción de la ciudadela de Villa Javier; para 1933 se habían construido 120 casas, un edificio en donde funcionaban las escuelas, una hospedería para jóvenes maestras, un teatro, el salón de sesiones y restaurantes. La otra obra importante del Círculo de Obreros fue la Granja Agrícola de Santa Teresa de Jesús en donde se cultivaban principalmente frutas y hortalizas, para luego ser vendidos y consumidos en la ciudadela. Con esta obra se organiza el grupo llamado Las Marías -fundamental para apoyar todas las obras del Círculo- que eran mujeres jóvenes y solteras, generalmente campesinas y huérfanas. El Círculo tenía un Consejo Administrativo que ayudaba en la orientación y administración, además del Consejo de Señoras Benefactoras que realizaban visitas domiciliarias, colaboraban en la organización de las festividades del Círculo y patrocinaban la consecución de donaciones. ${ }^{57}$ Posteriormente, el Círculo de Obreros extendió sus actividades fuera de Bogotá. La Caja de Ahorros fue la actividad que le permitió cierta difusión a nivel nacional. En 1929 se funda en Facatativá una Caja de Ahorros y dos escuelas, una para niñas y otra para niños, gracias al legado recibido de parte del señor Manuel Vicente Umaña. Posteriormente se fundan sucursales de la Caja de Ahorros en Sogamoso en 1932, en Duitama en 1933, en Manizales en 1941, en Pamplona y Málaga en 1942, en Cali en 1943 y en Tunja en 1945. Se complementaba esta actividad con escuelas para niños y niñas. Para 1961 asistían 2.148 niños y 2.358 niñas a todas las escuelas del Círculo de Obreros. ${ }^{58}$

\footnotetext{
${ }^{57}$ Ver María Casas, El Padre Campoamor y su obra El Círculo de Obreros, Bogotá: Fundación Social, 1995 [primera impresión en 1953] y Rocío Londoño y Alberto Saldarriga, La Ciudad de Dios en Bogotá. Barrio Villa Javier, Bogotá: Fundación Social, 1994.

${ }^{58}$ Alberto Martínez, Carlos E. Noguera y Jorge O. Castro, Educación, poder moral y modernización. Historia de la acción educativa de la Fundación Social. 1911-1961, Bogotá: Fundación Social, 1996, p. 32.
} 
Por otro lado el Círculo de Obreros de Bogotá se difundió como base para la formación de organizaciones políticas. En 1924 se establece la organización de los gremios de los obreros católicos, cuyos miembros se apoyaban en la doctrina social de la Iglesia y en la propia Iglesia Católica, estimada como un pilar central del orden social, lo que implicaba, entre otras cosas, fomentar el matrimonio católico, respetar la propiedad privada, combatir los excesos en la bebida, fomentar la instrucción en todos los niveles, el establecimiento de cajas de ahorros y la construcción de vivienda. En 1925 el Círculo de Obreros de Bogotá, en representación de los gremios matriculados de agricultura, albañiles, alfareros, aserradores, canteros, carreteros, carpinteros, constructores, ebanistas, electricistas, empleados, escultores, fundidores, grabadores, herreros, joyeros, latoneros, mecánicos, ornamentadores, peluqueros, pintores, pirotécnicos, plateros, relojeros, sastres, talabarteros, tapiceros, tipógrafos y zapateros, consideró:

que el llamado Congreso de Obreros, reunidos el año pasado en la capital de la República, no era representación genuina de la clase obrera, pues resultó una junta de carácter político, antisocial y antirreligioso, en completa disonancia con los sentimientos católicos de la inmensa mayoría de los obreros del país, que sus sectarias disposiciones no resolvieron ninguno de los problemas sociales, y dejaron a la clase obrera en la misma postración y miseria en que se encontraba; y que los principios allí proclamados ofrecen ancho campo a las ambiciones personales de algunos agitadores que pretenden medrar y entrar en la burguesía, sirviéndose como peldaño de la ignorancia e inexperiencia de muchos infelices obreros. ${ }^{59}$

El liderazgo del Círculo de Obreros en la organización gremial obrera estaba ligado a uno de los objetivos de la Acción Católica, que para esa época ya estaba conformada en Colombia. En sus inicios, alrededor de 1913, la Acción Católica se asemejaba más a las sociedades privadas de ayuda a los necesitados, puesto que sus propósitos eran “el conservar al pueblo en la fe y en las sanas costumbres, y el atraer a los extraviados y viciosos al buen camino, para de ese modo, conservar la paz social y procurar la salvación de las almas”; declarando que sus medios se reducían “a instituciones de carácter

\footnotetext{
${ }^{59}$ Londoño, Rocío y Gabriel Restrepo, Diez Historias de Vida “Las Marías”, Fundación Social, Bogotá 1995, (pp. 128 y 129).
} 
económico y de instrucción y educación cristiana que se dará a los obreros y sus hijos”. 60 En el Congreso Eucarístico de Bogotá y en el Congreso Mariano de 1919 la Acción Católica ayudó a promocionar la idea del catolicismo social. ${ }^{61}$ En 1923 Monseñor Vicentini reorganizó la Acción Católica con el imperativo de la justicia social y de la caridad cristiana. $^{62}$ En 1944 la coordinación de la Acción Católica fue encomendada a los jesuitas, porque eran ellos quienes la habían liderado prácticamente desde el inicio, y fue ese el momento en que la Acción Católica alcanzó en Colombia una dimensión nacional e institucional, basada principalmente en el desarrollo del sindicalismo católico. Para 1950 la Acción Católica estimaba tener 120.000 miembros urbanos y 200.000 miembros rurales. ${ }^{63}$

Con la misma orientación fueron creados los Patronatos Obreros en Medellín, dado el crecimiento acelerado del trabajo industrial femenino en la ciudad. El primero de ellos se crea en 1912 bajo la dirección de los jesuitas vinculados a la Acción Católica, con el objetivo de poseer una institución “que fuera como un asilo en que se recojan las hijas del trabajo para ganarse honradamente la vida, aprender los peligros del mundo y las verdades fundamentales que les sirvan como escudo para el porvenir". ${ }^{64}$ En los primeros años el Patronato fue impulsado y sostenido por la Compañía Colombiana de Tejidos (Coltejer), por la fábrica de Escobar, Restrepo y Cia., por la Compañía Industrial Unida de Cigarrillos, la fábrica de Tejidos Hernández, la fábrica de Tejidos de Jacinto Arango y Cia. y la fábrica de Fósforos Olano. El Patronato de Obreras se conformó con una junta directiva conformada por mujeres con el apoyo de sacerdotes jesuitas. Se estructuraron sus diferentes actividades por medio de secciones, un poco siguiendo el modelo de la Sociedad de San Vicente de Paúl. La primera en crearse fue la Sección de Conferencias Religiosas, la cual tenía que visitar las fábricas e invitar y convencer a las obreras para que asistieran a las conferencias dictadas por los padres jesuitas mensualmente. Igualmente se inicia la Sección

\footnotetext{
60 “Acción Social Católica 1913” en Conferencias Episcopales de Colombia, Bogotá, 1956, vol. 1, (pp. 5354). Por ejemplo en 1918 se había creado en Barranquilla el Centro de Acción Social que pretendía realizar sólo las obras económicas de Acción Social Católica.

${ }^{61}$ Cárdenas, Eduardo "La Iglesia Colombiana”, en: Aldea, Q y Eduardo Cárdenas, Manual de Historia de la Iglesia, Herder, Barcelona, 1987, t. x. (pp. 1110-1137).

${ }^{62}$ Bidegaín de Uran, Ana María, Iglesia, pueblo y política. Un estudio de conflicto de intereses. Colombia 1930 - 1953, Universidad Javeriana, Bogotá, 1985.

${ }^{63}$ Cárdenas, Eduardo, La Iglesia Hispanoamericana en el siglo XX, Mafre, Madrid, 1992, (p. 200). Entre 1930 y 1950 la Acción Católica fue organizada también en Argentina, Chile y Cuba.

${ }^{64}$ Mayor Mora, Alberto, Ética, trabajo y productividad en Antioqui. Una interpretación sociológica sobre la influencia de la Escuela Nacional de Minas en la vida, costumbres e industrialización regionales, Tercer Mundo, Bogotá, 1984, (p. 260.)
} 
de Restaurantes, que repartía sopas entre las obreras, suministrando entre 1912 y 1919, 93.200 platos de sopa. ${ }^{65}$ También se fundó la Sección de Socorros Mutuos, que con el aporte mensual de las obreras conformaba un fondo para ayudar a aquellas que sufrieran enfermedad y en 1915 se nombró un médico que atendía a las obreras del Patronato. En 1914 se crea la Sección Dormitorio de San Javier, en donde se les facilitaba vivienda a las obreras solteras que no fueran de Medellín, bajo el cuidado de las Hermanas de la Caridad de la Presentación. Se inicia con 4 obreras y para 1919 albergaba hasta $150{ }^{66}$ En ese mismo año se funda la Sección de Caja de Ahorro, para fomentar el ahorro entre las obreras que pertenecían al Patronato. En 1915 se crea la Sección de Culto, que intentaba no sólo organizar las conferencias religiosas, que para esa época eran ya semanales, sino también fomentar los ejercicios espirituales, que cubrían a todo el personal de las fábricas. Esta Sección de Culto estaba apoyada por la Congregación de Hijas de María, que fomentaba la práctica de la piedad y que para 1919 tenía 500 socias. ${ }^{67}$ Ellas organizaban las conferencias, las misas, las primeras comuniones y formaban coros que acompañaban las eucaristías. Ese mismo año se creó la Sección de la Escuela Dominical, mediante la cual se daban clases de corte y de bordado, de lectura, escritura, aritmética, gramática y cocina. Se calculaba una asistencia de 130 a 150 obreras cada domingo. ${ }^{68}$ La asistencia regular a esta escuela les daba a las obreras derecho a usufructuar de los beneficios del Patronato. Hacia 1919 había unas 820 obreras inscritas.

En 1916 las secciones en el Patronato se incrementaron. Aparece la Sección de Propaganda, que estaba encargada de fomentar la práctica de la buena lectura, para lo cual distribuían en las fábricas periódicos, folletos y revistas. La Sección de Recreo, que fomentaba veladas artísticas, reuniones musicales, paseos, rifas y celebración de aguinaldos. Su objeto era “dar a las obreras algunos ratos de solaz... de este modo las pobres obreras pasan horas muy agradables sin que por ello pierdan el amor al trabajo”. 69 Igualmente se crea la Sección de Colocaciones, con el objetivo de ayudar a buscar trabajo a las obreras que no tenían empleo, a través de contactos que obtenía el Patronato y de sus recomendaciones, de las que se esperaba constituyeran una buena carta de presentación.

\footnotetext{
65 Ibíd, p. 266.

${ }^{66}$ Ibíd, p. 264.

${ }^{67}$ Ibíd, p. 262.

68 Ibíd, p. 265.

${ }^{69}$ Ibíd.
} 
Entre 1916 y 1919 el Patronato ayudó a conseguir empleo a 307 obreras de 599 que lo solicitaron. ${ }^{70}$ La otra Sección fue la de Caja de Préstamos, para que las obreras lograran conseguir ayuda, sobre todo para vivienda, con la seguridad de que podían pagarlo; al año siguiente se creó la Sección de Caja Dotal, para que las obreras ahorraran para el momento de su matrimonio. En 1918 se funda la Escuela Tutelar que atendía a personas diferentes a las obreras, estaba orientada a recluir niñas indigentes o “descarriadas” y darles una educación adecuada, para que luego, de ser posible, fueran obreras. En 1919 se crea la Sección del Sindicato, con la idea de formar un sindicato que agrupara a las obreras de diferentes fábricas de la ciudad, con la esperanza de conformar un solo grupo obrero, participando de una sola organización. En ese año tenían 215 filiales. Su primera tarea fue la de oponerse a la fiesta del Primero de Mayo organizada por la Sociedad Socialista de Medellín. Para este fin se repartieron hojas volantes explicando los peligros de aquella celebración. El 4 de mayo las obreras del Patronato celebraron el día del trabajo con una misa y una velada recreativa, a la cual asistieron alrededor de 1.300 obreras. ${ }^{71}$ Para 1918 el Patronato de Obreras de Medellín contaba en 1918 con 2.164 obreras.

Al lado de las actividades de la Acción Social Católica, otras instituciones continuaron atendiendo a la población más necesitada y otras nuevas fueron creadas tanto en la ayuda institucional como en la domiciliaria. En la ayuda domiciliaria la Sociedad de San Vicente de Paúl continúo siendo la líder con la entrega de sus bonos familiares y sus otras obras como lo hemos señalado anteriormente. Tal vez la diferencia entre el comportamiento y las obras de la Compañía de Jesús y de la Sociedad de San Vicente de Paúl residió en que las organizaciones lideradas por los jesuitas se vincularon mucho más a los procesos de participación sindical y política que las nuevas encíclicas y evoluciones de la Doctrina Social de la Iglesia autorizaban y su atención se centró más en la población obrera. La Sociedad mantuvo su ayuda domiciliaria de forma amplia hacia a la población necesitada.

En cuanto a la ayuda institucional, el incremento fue notable. Si bien la creación de la mayoría de los establecimientos se concentró en las ciudades más grandes, algunos empezaron a ser fundados en las ciudades medianas. Las regiones más dinámicas en la ayuda institucional fueron Cundinamarca y Antioquia, dos de las regiones más activas

\footnotetext{
${ }^{70}$ Ibíd, p. 264.

${ }^{71}$ Ibíd, p. 267.
} 
económicamente también. Hubo una proliferación de instituciones y fueron más flexibles y capaces de realizar nuevas formas atención. Los conceptos y las prácticas de estas instituciones se derivan de nociones de la obligación moral, del deber religioso, de las exigencias y expectativas sociales. Los patrones de la ayuda institucional siguieron frecuentemente los modelos europeos, particularmente los franceses. En cuanto hacía referencia a políticas sociales, a ideas y prácticas de ayuda a los pobres y a las estructuras de los establecimientos; estos patrones fueron reforzados por las órdenes religiosas francesas, especialmente las femeninas, que llegaron a Colombia desde mediados del siglo XIX. Algunas experiencias latinoamericanas, como la chilena, también fueron de ejemplos a seguir en el campo de la ayuda institucional. La fundación de establecimientos por iniciativa privada aumentó considerablemente con ventaja sobre las creaciones oficiales a principios del siglo XX. Médicos, religiosos, mujeres, empresarios y autoridades políticas contribuyeron todos, de alguna forma, en estas fundaciones. La participación de las mujeres, seculares y religiosas fue de nuevo, importante y notoria, lo que les permitió a éstas entrar de alguna manera a la vida pública de forma aceptable y estimada. La participación de las órdenes religiosas en la ayuda institucional fue sobresaliente, cada congregación aportó su especialización en la atención y la ayuda a los pobres.

Varias pautas se desarrollaron en la ayuda institucional. Los establecimientos de salud dependieron del Estado y se esparcieron más a través del país. Se contaban 127 hospitales en la región central de Colombia para 1927. Había al menos un hospital en cada capital de departamento, en algunas ciudades más de uno, como era el caso de Bogotá, Medellín y Pasto. Antioquia era el departamento que tenía más hospitales: 36. Existía un hospital en casi todos sus municipios. Seguido por Boyacá que tenía 25 y Cundinamarca, incluida Bogotá, que tenía $24{ }^{72}$ De estos la mayoría era estatal, tan sólo en el caso de las ciudades más grandes, el hospital principal era estatal y los otros se habían fundado por iniciativas de médicos o sociedades científicas, como en el caso de Bogotá en donde se crearon el hospital de La Misericordia en 1897 -liderado por el doctor José Ignacio Barberi para atender especialmente a los niños enfermos- y el de San José en 1926 por la Sociedad de Cirugía de la ciudad.

\footnotetext{
${ }^{72}$ Historia de las Leyes, Imprenta Nacional, Bogotá, 1934, pp. 405-445.
} 
Dentro de las actividades en el área de salud cabe resaltar el programa de La Gota de Leche. El hospital principal de Bogotá conjuntamente con la Sociedad Pediátrica fueron los líderes del programa que se inicio en $1919,^{73}$ programa que recibió la colaboración de un grupo de señoras encargadas de recoger fondos. ${ }^{74}$ El principal objetivo era "ejercer una supervigilancia médica sobre los niños de la clase pobre por medios de institutos de puericultura y de dispensarios lactantes donde se pesan y examinan los párvulos, y se preparan y se enseñan a preparar a las madres la leche y fórmulas alimenticias adecuadas para los niños”. ${ }^{75}$ Este programa hace parte de estrategias relacionadas con las nuevas ideas de higiene ya incorporadas y para responder a la inquietud generalizada sobre el alto índice de mortalidad infantil. El programa de la Gota de Leche fue acompañado con el programa de salas-cuna, que para el caso de Bogotá se implementó en el Hospicio. Estos programas se habían desarrollado en la década 1910 con gran éxito en Argentina, Chile y Uruguay, lo que sirvió como ejemplo para que se extendiera en muchas partes de Colombia. ${ }^{76}$ En 1917 en Medellín, por iniciativa del arzobispo y la Asociación de Madres Católicas, bajo la dirección de las Hermanas de la Caridad y con el apoyo del cuerpo médico de la ciudad, se inició el programa para atender a los huérfanos y a los niños de familias pobres, ${ }^{77}$ que en 1925 atendía a 100 niños. En 1919 en Cartagena un grupo de señoras con el apoyo de los médicos y la municipalidad iniciaron el programa $\mathrm{y}$, posteriormente, fue también establecido en Bucaramanga, Popayán y Sonsón. En Medellín el programa fue extendido por la creación del hospital infantil Club Noel, que se inició en un edificio inacabado anexo al hospital, que le fue donado a dicha sociedad en $1923 .^{78}$ Esta Sociedad se había iniciado con el objetivo de donar regalos en la navidad a los niños pobres. En 1924 tenía 60 camas y el programa de La Gota de Leche. De una manera similar, las Damas Católicas de Cali que tenía la misma costumbre de dar regalos de navidad a los niños pobres, recibieron en 1924 una donación de un lote para construir un hospital infantil, y en 1934 abrieron el Hospital Infantil Club Noel.

\footnotetext{
${ }^{73}$ AGN, Sección República, Ministerio de Gobierno, t. 6, fol. 129-131.

${ }_{74}^{74}$ AGN, Sección República, Ministerio de Gobierno, t. 6, fol. 111-112.

${ }^{75}$ Informe que rinde la Junta General de Beneficencia de Cundinamarca a la Asamblea Departamental en su sesiones de 1922. Imprenta La Luz, Bogotá, 1922.

76 Asunción Lavrin, Women, Feminism and Social Change in Argentina, Chile and Uruguay, 1890-1940, Lincoln: Nebraska University Press, 1995, pp. 97-124.

${ }^{77}$ AGN, Sección Republica, Ministerio de Gobierno, t. 6, fol. 276-278 y t. 8, fol. 17-18.

${ }^{78}$ Patricia Castro, op. cit., p. 81.
} 
El panorama de los establecimientos de protección era más variado. Las instituciones para indigentes fueron un asunto estatal dado que hacia 1920 había ya un consenso sobre la prohibición de la mendicidad en las calles, y fuertes disposiciones legales se decretaron para controlar la presencia de los mendigos en ellas. ${ }^{79}$ Los vagos tenían que ser reeducados y reformados. ${ }^{80}$ La ley implicaba igualmente la promoción y fundación de asilos en la mayoría de las capitales de los departamentos. En ese momento había asilos para indigentes en Bogotá, Medellín, Cali, Cartagena, Tunja, Pasto y Cúcuta a cargo de los gobiernos municipales. Los establecimientos para los niños tuvieron un notable incremento después de la década de 1910. En este tiempo los orfanatos fueron vistos como la siguiente institución para los niños huérfanos después de las salas-cunas o el hospicio. La protección y amparo de los niños huérfanos y pobres fue una de las actividades con mayor dinámica en esta época, y se hizo evidente a través de la fundación y creación de este tipo de establecimientos por todo el país. Sin embargo, la mayoría de iniciativas salieron de ciudadanos, de asociaciones laicas, algunas apoyadas por órdenes religiosas o establecidas por ellas mismas. La división por sexo en estas instituciones era clara. El número de orfanatos para niñas era mayor que el de los niños; a las niñas, como a las mujeres, se les veía como un grupo más vulnerable. Los orfanatos fueron sitios de protección para los niños entre siete y catorce años, pero también fueron vistos como instituciones educativas. La educación era vista como la mejor manera de proveer una vida respetable después del orfanato, y particularmente la educación para el trabajo fue vista como la mejor forma de garantizar un ahorro mientras los niños permanecían en el establecimiento y como un ingreso para su vida futura. Fuera de los orfanatos de Bogotá y Medellín que albergaban a un número significativo de niños, la mayoría en el resto del país, fundados en las capitales de los departamentos, fueron pequeños. En Pasto, por ejemplo, fue fundado un orfanato para niñas por el obispo en 1886 con el appoyo del gobierno departamental y municipal y dirigido por las Hermanas Betlehemitas; en 1924 tenía 24 niñas. ${ }^{81}$ En Cartagena el orfanato tenía en 193440 niñas y existían otros pequeños orfanatos en Armenia, Pamplona, Socorro, Chinácota, Caloto, Zipaquirá y Cartago.

\footnotetext{
${ }^{79}$ El Tiempo, Bogotá, 11 de marzo de 1920.

${ }^{80}$ El Tiempo, Bogotá, 16 de marzo de 1920.

${ }^{81}$ Santander, Alejandro, Biografía de Aldana y Coreografía de Pasto, Pasto, 1895, (p. 98).
} 
A la par de está dinámica en la ayuda a los más necesitados, los gobiernos de la década de 1920 parecen haberse planteado algunos cambios importantes respecto de las estructuras tradicionales del aparato de beneficencia, buscando sentar las bases de una asistencia pública realmente secular y moderna. Este proceso de todas maneras tomó varias décadas para llegar a su punto de arribo, en caso de que aceptemos que la sociedad colombiana ha conquistado ese punto de secularización e independencia estatal de la Iglesia en el terreno de la asistencia social, lo cual no debería ser aceptado como algo evidente. Los planteamientos de esos gobiernos modernizantes de principios del siglo $\mathrm{XX}$, al parecer sinceramente empeñados en la reforma de la sociedad por la vía del trabajo productivo y la creación de riqueza, se centraban en introducir de forma estandarizada la práctica de la higiene y la cientifícidad de la atención médica, como también la educación para el trabajo y el fomento al ahorro. Y por otro lado buscaban introducir un manejo centralizado, supervisado y controlado de las actividades de todos los establecimientos de asistencia pública. Estos cambios estaban enmarcados en un contexto de discusión más amplio que era la reflexión sobre la idea de caridad y de beneficencia. Uno de los mejores ejemplos para ilustrar estas discusiones son las ideas expresadas por el médico Marcelino Vargas, quien había trabajado varios años en la Junta General de Beneficencia de Cundinamarca que había sido fundada en 1869 como el primer ente estatal de beneficencia. La Junta era responsable de la administración de todas las propiedades relacionadas con los establecimientos de beneficencia, tenía que diseñar los reglamentos para el funcionamiento de los establecimientos, designar las personas responsables de su administración, supervisar y controlar las cuentas y encontrar suficientes ingresos para el desempeño normal. Las críticas a la Junta y sus establecimientos, que en 1919 eran el Hospital de San Juan de Dios, el Asilo de Locos, el Asilo de Locas, el Hospicio, el Asilo de San José de Niños Desamparados, el Asilo de Preservación para Niñas, el Asilo de Indigentes de Mujeres y la Colonia de Mendigos de Sibaté, fueron publicadas primero en el periódico El Diario Nacional, artículos que provocaron respuestas y aclaraciones y que posteriormente fueron publicados como un libro titulado La Beneficencia en Cundinamarca. ${ }^{82}$ Uno de los puntos que Marcelino Vargas más discutió fue el que la ayuda institucional no debería concebirse

\footnotetext{
${ }^{82}$ Vargas, Marcelino, La Beneficencia en Cundinamarca, Casa Editorial Arboleda \& Valencia, Bogotá, 1920.
} 
más como acción de caridad o beneficencia sino que debería considerarse un asunto de asistencia pública:

Basta por hoy. Ojalá que la Junta de Beneficencia, integrada como está por personas inteligentes y honorables, se haga cargo alguna vez de que en sus manos está la asistencia pública de Cundinamarca y que los establecimientos que maneja no son de caridad, como los califica el informe tantas veces mencionado. ${ }^{83}$

Unas páginas más adelante añade:

El Nuevo Tiempo y el señor Síndico del Hospital se empeñan en confundir la beneficencia pública con la privada y en sostener que los establecimientos a cargo de la Junta General de Beneficencia son de caridad, sin considerar que así le hacen mal a la entidad misma y desconocen la obligación en los poderes públicos de proveer suficientemente a ramo tan importante de la administración. La máxima evangélica Amaos los unos a los otros, no tiene que ver con el Estado. Este no hace ni debe hacer obras de caridad auxiliando establecimientos destinados al servicio de los menesterosos... Muchos de los errores en que se ha incurrido en esto de la Beneficencia, y muchas de sus deficiencias, provienen de la confusión de beneficencia por caridad, de beneficencia por asistencia pública. ${ }^{84}$

Otro aspecto importante que Marcelino Vargas trae a discusión consiste en quién debería ser el responsable de la ayuda institucional:

En todas partes del mundo este organismo que aquí llamamos beneficencia se llama de asistencia pública y funciona organizado como un ramo muy importante del gobierno. El nombre de beneficencia que aquí le hemos dado a esa dependencia oficial, y la manera despreciativa con que se la ha mirado y administrado, perturban el criterio con que se juzga, haciendo creer que es asunto de caridad y filantropía, y que debe tratarse como tal lo que es simplemente un deber administrativo. A los establecimientos que el gobierno costea y que son o deben ser parte integrante de la administración pública, en donde no entra la caridad como móvil, sino el cumplimiento de ineludibles deberes gubernativos, debemos darles su verdadero nombre y organizarlos y

\footnotetext{
${ }^{83}$ Ibíd., p. 10.
}

${ }^{84}$ Ibíd., p. 17. 
reglamentarlos bajo una oficina pública, con su personal de empleados, sus rentas, su materia, etc. ${ }^{85}$

Después de varias discusiones públicas alrededor de la beneficencia, en 1921, en la Ordenanza número 51, el Estado incluye el nuevo concepto de asistencia pública. ${ }^{86}$ La introducción de este nuevo concepto no trajo cambios sustanciales en las prácticas de la ayuda institucional, la Junta continuó a cargo de los mismos establecimientos, aplicando y mejorando los mismos programas que hasta ahora venía implementando. Los cambios estaban más relacionados con la manera en que la Junta debería manejar los recursos. Sin embargo, el presidente de la Junta General de Beneficencia en 1922, Francisco Samper, expresó sus temores:

Esa reforma será muy conveniente, y aún necesaria, cuando las entradas pecuniarias justifiquen la existencia de empleados superiores técnicos y bien remunerados; por el momento sería preciso disminuir las partidas destinadas a alimentos y drogas para costear en cambio los sueldos del personal directivo superior, el cual carecería por lo demás, de campo de acción para sus conocimientos e iniciativas que encallarían en todas partes en la falta de recursos. De otro lado la formación de una burocracia en la Beneficencia retraería el apoyo de los particulares, cuyas donaciones, herencias, legados y servicios personales constituyen un importantísimo renglón de entradas para esta rama de la administración departamental. En cuanto a la creación de una tesorería general que centralice las cajas de los Establecimientos, quizás se imponga cuando la situación y orden del Fisco Nacional le permitan atender, puntualmente y sin constantes cobros, el pago de auxilios; por el momento es irreemplazable la acción simultánea de ocho a diez caballeros de grande influencia social, quienes por caridad y filantropía desempeñan las sindicaturas, y recaudan las rentas de los establecimientos y cobran los auxilios con mayor asiduidad que si se tratase de sus intereses particulares. ${ }^{87}$

Hacia 1920 estos nuevos planteamientos, discusiones y temores manifiestos llevaron a que el Estado adoptara una política social más diáfana, sobre todo en lo concerniente a la ayuda institucional, sin embargo subsistieron muchas ambigüedades, principalmente en la administración de los establecimientos y el manejo de los recursos. Si bien mucha de las informaciones aquí estudiadas perecen comprobar la idea de que en el último tercio del

\footnotetext{
${ }^{85}$ Ibíd., p. 28.

${ }^{86}$ Compilación de Leyes y Ordenanzas de la Beneficencia y Asistencia Social de Cundinamarca. 1869-1942, Talleres de la Imprenta del Departamento, Bogotá, 1942, (p. 63).

${ }^{87}$ Informe que rinde la Junta General de Beneficencia a la Asamblea Departamental en sus sesiones de 1922, Imprenta La Luz, Bogotá, 1922.
} 
siglo XIX se abre paso por primera vez a una realidad específica denominada "lo social" en la agenda de los gobiernos, el trayecto hacia las políticas estatales permanentes de atención hacia los grupos sociales más vulnerables de la sociedad sería un proceso lento y gradual.

Como habíamos señalado, en los gobiernos liberales de la década de 1870 se creó la Junta de Instrucción Pública separada de la beneficencia. Posteriormente en 1887 se establecieron la Junta Central de Higiene y las Juntas Departamentales de Higiene en cada departamento. Estas Juntas eran promovidas y administradas por médicos, quienes tenían la responsabilidad de organizar la salud pública en el país. Antes de que estas instituciones fueran establecidas, las acciones relacionadas con salud pública eran tomadas sólo en condiciones de emergencia, por ejemplo, cuando alguna epidemia se expandía. En 1918 la Junta Central de Higiene fue transformada en la Dirección Nacional de Higiene; el aspecto más importante de este cambio fue el que la Dirección tenía la capacidad de decretar legislación relacionada con la problemática de la higiene y sanidad, sin interferencia de otras esferas políticas: adquirió completa autonomía. ${ }^{88}$ En 1924 fue creado el Ministerio de Instrucción y Salubridad Pública. La sección de salud fue dividida en dos: higiene y asistencia pública. La división de higiene tenía la responsabilidad de controlar la infraestructura urbana -abastecimiento de agua, alcantarillado y basuras- y las epidemias, mantener actualizadas las estadísticas y llevar a cabo campañas de vacunación. La división de asistencia pública tenía la responsabilidad de administrar las instituciones como hospitales, asilos y orfanatos, la protección para la infancia y las habitaciones para los pobres. ${ }^{89}$ Podemos constatar no sólo los primeros cambios en las denominaciones que el Estado fue introduciendo en política social sino también cambios efectivos de reorganización de las funciones del Estado respecto a la seguridad social.

\section{III}

Considerado el panorama del problema, podemos ahora intentar trazar algunas características generales. Los inicios modernos de la asistencia social en Colombia pueden

\footnotetext{
${ }^{88}$ Repertorio de Medicina y Cirugía, vol. xviiii, no. 1, Bogotá, 1926.

${ }^{89}$ Proyecto de Ley sobre Higiene social y asistencia pública, Imprenta Nacional, Bogotá, 1924.
} 
ser rastreados en los años que van de 1870 a 1920, años que corresponden tanto a gobiernos liberales como conservadores. Las orientaciones en la asistencia -de la caridad y la beneficencia a la acción social y la asistencia pública- y su paulatina transformación reflejan los primeros intentos de consolidar, modernizar, sistematizar y ampliar la ayuda institucional y domiciliaría tanto de las asociaciones privadas como de organismos estatales, de manera muy semejante a lo que se encuentra en Europa y en otras sociedades latinoamericanas. Salud a la población pobre en general, educación básica y técnica a niños, artesanos y obreros; protección a los niños y ancianos; asistencia con bonos, alimentos y ropa y vivienda a familias; bolsas de empleo y cajas de ahorro a artesanos y obreros, fueron las actividades más desarrolladas tanto por agentes privados como por agentes públicos, lo que puede significar que si bien estas actividades estaban en el marco general de la asistencia social, algunas de estas empezaron a incorporar elementos que iban un poco más allá de la asistencia -en el sentido más tradicional-, como en el caso de la educación y la capacitación laboral. Como es de suponer, las primeras preocupaciones modernas en torno a la asistencia recayeron sobre la población más desvalida, en forma genérica, y paulatinamente la atención se fue especializando en grupos como los niños, los obreros, los artesanos, los ancianos y las mujeres. En general buena parte de las acciones privadas y públicas se adelantaron de forma conjunta y complementaria, un hecho que se puede constatar de varias formas, pero que se observa de manera muy nítida cuando se observa el concurso de fuentes privadas y estatales de financiación que concurrían de manera indistinta a la financiación de labores de asistencia social. ${ }^{90}$

Los grupos de personas que sobresalen en la realización de la actividad de asistencia social fueron los religiosos -curas y monjas-, profesionales -de muy diversa formación, aunque sobresalen los médicos-, hombres y mujeres que generalmente pertenecían a medios sociales que se pueden identificar como de clase media y alta. Se destaca también la participación voluntaria, un hecho que puede estar explicado en parte por el llamado del catolicismo a participar en este tipo de actividades de manera directa y no sólo a brindar apoyo a través de colaboración económica. Los religiosos y las religiosas fueron al parecer las personas más idóneas para realizar las tareas de dirección y administración de estas

\footnotetext{
${ }^{90}$ Las instituciones estatales recibieron legados y donaciones y las instituciones privadas auxilios del Estado y múltiples exenciones.
} 
instituciones en esa época. Sin embargo no se puede dejar de lado el hecho de que en algunas congregaciones religiosas, tanto de hombres como de mujeres, pero de manera acentuada en estas últimas, sus miembros eran formados para actuar en este campo y ofrecer servicios de asistencia social, de manera particular en el caso de las órdenes religiosas que tenían su origen en Francia. ${ }^{91}$

La mayor parte de la actividad de asistencia social tuvo como epicentro principal a medios urbanos, grandes y medianos, aunque la actividad fue mucho más concentrada en las ciudades colombianas que muestran para esa época mayor crecimiento y dinamismo. Esta distribución geográfica de la asistencia social en principio sorprende, dado que para esa época la población en Colombia vivía en su mayoría en el campo. ${ }^{92}$ Esta concentración de la asistencia social en medios urbanos se encuentra también como una constante en Europa, como lo muestran los estudios históricos sobre la pobreza, en los que se constata también que la atención a la población pobre desde tempranas épocas tuvo como escenario principal a las ciudades, ${ }^{93}$ en donde posiblemente la pobreza se hacía más visible, más “peligrosa” y más apremiante en los campos; o tal vez ocurría, como en ocasiones se ha pensado, que en las áreas rurales existían más ayudas informales -muy poco registradas en los archivos oficiales-, o que las instituciones de asistencia se fortalecían y consolidaban si mantenían vínculos más cercanos con el poder político establecido en las capitales.

\footnotetext{
${ }^{91}$ Ver: Castro, Beatriz, “Charity and Poor Relief in a Context of Poverty: Colombia, 1870 - 1930”. Tesis Doctoral, Universidad de Oxford, 2001.

${ }^{92}$ En 1938 un 29\% de la población colombiana vivía en las ciudades y al final del siglo XX, un 70\%.

93 Ver: Jütte, Robert, Poverty and Deviance in Early Modern Europe, Cambridge Univeristy Press, Cambridge, 1994, y Geremek, Bronislaw, Op. Cit.
} 